\title{
O TECER DA ARTE COM A PSICANÁLISE
}

\author{
PHILIPPE WILLEMART
}

Universidade de São Paulo

\section{Resumo}

Trabalhar hoje as relações literatura-psicanálise exige do crítico não só um conhecimento dos dois saberes, mas a flexibilidade suficiente para não confundir os objetivos dos dois campos e estabelecer as relações não a partir da psicanálise nem da literatura, mas da procura de uma compreensão maior do ser humano, objetivo comum compartilhado por todas as ciências humanas. No entanto, os dois saberes se diferenciam no objeto e na estratégia, o que será detalhado no texto que segue. As artes, tendo o poder de suspender o sujeito, contribuem para o conhecimento não por serem admiradas, mas, segundo o narrador proustiano, por mergulhar o homem na cultura, oferecendo-lhe outra visão do mundo ou outro sentido para certos acontecimentos. A psicanálise, desfazendo o estabelecido e os preconceitos, exige uma narrativa do analisando que lhe permita reconstituir uma história singular. A partir da mesma problemática nos perguntamos se escrever, pintar, esculpir ou inventar uma melodia substitui uma análise.

Palavras-chave

Psicanálise; Proust; arte; literatura; sujeito; cultura.

\begin{abstract}
Working on the relations between literature and psychoanalysis today demands from the critic not only knowledge of the two areas, but also enough flexibility to avoid confusing the objectives of the two fields and to establish relations not only in one of the two perspectives but in the search for a larger understanding of the human being, the common objective shared by all of the humanities. However, the two areas differ in the object studied and in the strategy adopted by the researcher, as will be detailed in the text that follows. The arts having the power to suspend the subject, contribute to knowledge not because they are admired, but, according to the Proustian narrator, because they envelop men in culture, offering them another vision of the world or different perceptions of certain situations. Psychoanalysis, by undoing prejudices and the established, demands from the analyzed a narrative that will allow for the reconstitution of a singular story. In conclusion, we inquire whether writing, painting, sculpting or inventing a melody substitute analysis.
\end{abstract}

Keywords

Psychoanalysis; Proust; art; literature; subject; culture.

O poeta tem acesso às fontes desconhecidas do conhecimento, inacessíveis ao psicanalista, insiste Freud na leitura da Gradiva. ${ }^{39}$ Corroborando essa afirmação com um exemplo tirado da Prisioneira de Marcel Proust, discordarei, entretanto, do fundador da psicanálise quando vê na análise do conto de Jensen apenas uma confirmação da clínica. A psicanálise e a arte têm certamente um objetivo comum compartilhado por todas as ciências

\footnotetext{
${ }^{39}$ Sigmund Freud, Délires et rêves dans la "Gradiva” de Jensen, Paris, Gallimard, 1948, p. 127.
} 
humanas, o conhecimento maior de ser humano, ${ }^{40}$ mas os dois saberes se diferenciam no objeto específico e na estratégia, o que espero mostrar no que segue.

Nos dias em que eu não descia à casa da Senhora de Guermantes, para que o tempo me parecesse menos longo durante aquela hora que precedia a volta de minha amiga, eu folheava um álbum de Elstir, um livro de Bergotte, a sonata de Vinteuil [...]. Então, como até as obras que parecem dirigir-se apenas à vista e ao ouvido exigem que para as saborear nossa inteligência espertada colabore estreitamente com esses dois sentidos, eu fazia sem querer sair de mim os sonhos que Albertine suscitara outrora quando eu ainda não a conhecia e que haviam sido apagados pela vida cotidiana. Punhaos na frase do músico ou na imagem do pintor como num cadinho, e deles alimentava a obra que eu lia. E sem dúvida esta me parecia, por isso, mais viva. Mas Albertine não ganhava menos em ser assim transportada de um dos dois mundos a que temos acesso e onde podemos situar alternativamente um mesmo objeto, em escapar assim à esmagadora pressão da matéria para espairecer nos fluidos espaços do pensamento. Eu me via de súbito e por um instante a sentir pela enfadonha moça afetos ardentes. Ela tinha naquele momento a aparência de uma obra de Elstir ou de Bergotte, eu experimentava por ela uma exaltação momentânea, vendo-a no recuo da imaginação e da arte. ${ }^{41}$

A vista e o ouvido do herói são despertados pela literatura de Bergotte, a pintura de Elstir e a música de Vinteuil, os três artistas de Busca do tempo perdido que serão sucessivamente modelos para o herói. $\mathrm{O}$ narrador constata que o conjunto provoca à sua revelia a intrusão de velhos sonhos presentes no eu. Isso significa que o livro, o quadro ou a melodia convocam uma dimensão inconsciente que, mergulhada nessas respectivas artes, as alimenta e as torna, se não mais vivas, ao menos mais pessoais. O efeito imediato é extrair a jovem do cotidiano, transformá-la em personagem de Bergotte e de Elstir e reavivar os sentimentos amorosos do herói por ela.

Em outras palavras, a arte transforma as personagens do sonho em personagens artísticas e desperta as paixões do sonhador que, por conseguinte, passará a amar não mais a Albertine com quem convive em sua casa, mas uma personagem de ficção. A vivência do cotidiano será apenas um ponto de partida para alçar a amada à dignidade de um objeto artístico. Jauss definiu o prazer estético como o prazer de si no prazer do outro. O herói proustiano descobrindo seu prazer nas obras lidas o comprova em parte.

As três artes citadas têm a capacidade de fazer vibrar o inconsciente e remexer em zonas de lembranças até então esquecidas. Todas as artes trabalham o inconsciente do público. O objetivo essencial da literatura, da pintura ou da música, da escultura ou da arquitetura etc., ou sua função estética não é primeiramente ser admirada; a beleza é apenas uma isca, para não dizer uma armadilha, destinada a atrair o olhar ou o ouvido. Comentando os escritos de Sade, Lacan escrevia:

A exigência, na aparência das vítimas, de uma beleza sempre classificada de incomparável [...] é uma outra história, da qual não nos podemos livrar com alguns postulados banais, forjados às pressas, sobre a atração sexual. Neles, veremos antes, a

\footnotetext{
${ }^{40}$ Philippe Sabot, Philosophie et littérature. Approches et enjeux d'une question, Paris, PUF, 2002.

${ }^{41}$ Marcel Proust, A prisioneira, trad. Manuel Bandeira, São Paulo, Globo, [s. d]., p. 51. Parece-me que, ao passar a limpo em francês, o copista esqueceu a terceira parte, claramente citada mais adiante. O Caderno 53 é explícito a esse respeito: "Quelquefois en l'attendant pour que le temps me semblait moins long, je prenais un livre de Bergotte je jouais quelque phrase mélancolique de Vinteuil" ["Por vezes, enquanto a esperava e para que o tempo me parecesse menos longo, pegava um livro de Bergotte, tocava alguma frase melancólica de Vinteuil"]. Proust, fólio 20 v, Caderno 53 (Transcrição inédita de Carla Cavalcanti e Silva).
} 
caricatura daquilo que demonstramos na tragédia, sobre a função da beleza: barreira extrema que proíbe o acesso a um horror fundamental. ${ }^{42}$

Baudelaire já aliava o horror ao infinito e o Belo:

Que tu viennes du ciel ou de l'enfer, qu'importe,

O Beauté ! monstre énorme, effrayant, ingénu!

Si ton oeil, ton souris, ton pied, m'ouvrent la porte

D'un Infini que j'aime et n'ai jamais connu!

De Satan ou de Dieu, qu'importe? Ange ou Sirène,

Qu'importe, si tu rends, - fée aux yeux de velours,

Rythme, parfum, lueur, ô mon unique reine ! -

L'univers moins hideux et les instants moins lourds. ${ }^{43}$

Entre o horror à morte, a beleza-armadilha e o infinito, o narrador proustiano desvela uma quarta dimensão inédita, um pouco mais alentadora, que corrobora certos argumentos filosóficos e psicanalíticos. A arte tem por função primordial introduzir e até mergulhar o homem na cultura, oferecer outra visão do mundo ou outro sentido para certos acontecimentos e, portanto, dizê-lo melhor.

Como isso se dá? Antes de introduzir as experiências passadas no livro, no quadro ou na melodia, a arte criou para si um espaço no qual circulam seus admiradores, o "espaço ou campo de gozo estético". ${ }^{44}$ O quadro, o livro ou a melodia se animam antes do olhar ou da escuta do leitor ou do ouvinte, e seu campo constituído de energia dispersa se concentra em torno do desejo do leitor ou do ouvinte, cujas lembranças ele capta.

A obra tem o dom de "suspender a continuidade hermenêutica do sujeito consigo mesmo e com a história - o sujeito vive o salto no vazio de sua própria mortalidade". ${ }^{45}$ Ela relança o sujeito até o ponto $\mathrm{K}$, anterior à sua própria vinda, isto é, ao nível máximo de negatividade antes do movimento de rejeição e de afirmação que o constitui como sujeito. ${ }^{46}$ Enfim, inscrita no campo do admirador constituído pelos três registros do inconsciente, o Real, o Simbólico e o Imaginário, a obra tem o poder de suspender e diluir o sujeito, aquele que se toma por um sujeito substancial, e lançá-lo para outro significante desconhecido de início.

Bastava o herói se lembrar do que vira e ouvira de Albertine outrora quando mal a conhecia e jogar suas imagens e seus comentários na obra que estava lendo ou na partitura

\footnotetext{
${ }^{42}$ J. Lacan, "Kant com Sade". Escritos. Rio, Zahar, 1998.p. 787. "O belo tem por efeito suspender, rebaixar, desarmar, diria eu, o desejo [...] insensível ao ultraje [...]. A função do belo sendo precisamente a de nos indicar o lugar da relação do homem com sua própria morte, e de nos indicá-lo somente num resplandecimento". Idem, A ética da psicanálise, Rio, Zahar, 1991. p. 290 e 354.

${ }^{43}$ Charles Baudelaire, "Hymne à la beauté", in Oeuvres complètes, Paris, Seuil, 1968, p. 54

${ }^{44}$ Philippe Willemart, Argüição na defesa de tese de João Augusto Frayse-Pereira. Inquietudes: arte $e$ psicanálise, Instituto de Psicologia, Universidade de São Paulo. 13 de dezembro de 2000.

${ }^{45}$ Gianni Vatimo, La fin de la modernité, trad. Charles Alunni, Paris, Seuil, 1987, p. 128. [ed. bras. : Idem, $O$ fim da modernidade, São Paulo, Martins Fontes, 1976].

46 "O propósito básico [desse livro] consiste apenas em mostrar que existem vários níveis de negatividade, sendo que o 'grande negativo' (ponto K) representa o nível mais profundo. Minha suspeita é de que, uma vez bem compreendido o ponto $\mathrm{K}$ - esse grau máximo do não - podemos ir nomeando, pouco a pouco, todas as outras estratégias menores do negativo e todos os modos da distância (não) e da aproximação (sim). Tal percurso é psicanaliticamente relevante na medida em que um inventário das negatividades permite repensar as categorias da neurose [...] e da psicose [...] a partir da negatividade radical do K". Juliano Pessanha, Sabedoria do nunca, São Paulo, Ateliê, 1999, p. 117-18.
} 
que folheava, para reviver uma paixão extinta. ${ }^{47}$ Swann já tinha vivido experiência semelhante ao escutar a pequena música de Vinteuil: "uma estranha embriaguez [...] em despojar o mais íntimo de sua alma de todos os recursos do raciocínio e fazê-la passar sozinha pelo filtro obscuro do som!". 48

O processo de criação e o continente, a passagem pelo filtro da arte, são os mesmos nas duas experiências embora o conteúdo e os resultados sejam diferentes. Já não é a alma de Swann que, mergulhada na arte, goza de uma felicidade que repousa sobre um sofrimento longínquo, mas os antigos sonhos do herói que, revitalizados pela arte, provocam "sentimentos ardentes", ou seja, o desejo sexual. As duas passagens pelo filtro da arte fazem referência a uma pessoa amada no passado, Odette ou Albertine, mas somente o sonho transporta o herói para além de si mesmo e transforma a personagem por uma espécie de transmutação.

As relações entre a arte e a realidade são aqui evocadas. Ou a personagem via a realidade por meio da arte - é Swann que se extasiava diante de Odette porque reconhecia nela o colo de uma virgem de Botticelli!- ou via a arte apenas a partir de sua imitação ou não da realidade - é o crítico Sainte-Beuve segundo Proust.

No trecho citado, temos uma nova postura. O ponto de partida já não é a realidade percebida diretamente ou por intermédio da arte, substituta de uma fantasia. $\mathrm{O}$ primeiro passo é uma atividade de leitura, de contemplação ou de escuta que evoca lembranças ou, no caso do herói, as da paixão, para transformá-las. Transportar ou operar um deslocamento das lembranças de Albertine para o mundo da literatura, da pintura ou da música não só reconstrói a personagem - é um processo de criação a mais -, mas também alça a antiga amante a tal nível que ela pode circular "nos fluidos espaços do pensamento" e despertar de novo a paixão do herói.

A arte tem o poder de "elevar o objeto à dignidade da Coisa", sublinhou Lacan bem mais tarde, mas, além disso, acrescenta o narrador proustiano, de exaltar a paixão do herói. Mallarmé já escrevia a Cazalis: "Saiba que sou agora impessoal, e não mais o Stéphane que você conheceu - mas uma aptidão que o Universo Espiritual tem de se ver e se desenvolver através do que eu fui", 49

Não seria essa uma maneira de situar a arte na sociedade? A arte permite reavaliar a realidade passada ou presente porque, instintivamente ou "sem querer" nota o narrador, comparamos nossa vida passada ou presente com ela. Lendo um romance ou uma poesia, escutando música, assistindo a uma peça de teatro ou a uma novela na televisão, admirando uma escultura ou um quadro ou deixando-nos embalar pela atmosfera de um filme, de uma catedral ou de um contexto mais amplo como uma cidade ou um vilarejo, mudamos muitas vezes e inconscientemente nossas representações, imitamos uma personagem, adotamos determinada expressão, sensibilizamo-nos com certa melodia, o grau de luminosidade de um quadro, a força de um gesto ou a atmosfera de uma paisagem.

Segundo Platão: só a imitação pode penetrar na fortaleza de um caráter; é com nossa alma, do mais fundo de nós, que imitamos continuamente o que vemos e ouvimos, as formas, os sons que habitam nossa memória e nossa imaginação. ${ }^{50}$

\footnotetext{
${ }^{47} \mathrm{O}$ narrador o dizia com outras palavras no último prototexto conhecido: "que a arte recolocava entre mim e ela aquelas distâncias da imaginação que tinham feito com que eu a amasse em Balbec quando não a conhecia". Fólio 20 v. Caderno 53.

${ }^{48}$ Idem, ibidem.

${ }^{49}$ Stéphane Mallarmé, Oeuvres complètes, edição apresentada, estabelecida e comentada por Bertrand Marchal, carta de 14 de maio de 1867, Paris, Gallimard, 1998, p. 714 (Pléiade).

${ }^{50}$ Walter Pater, Essai sur l'art et la Renaissance, trad. Anne Henry, Paris, Klincksieck, 1985, p. 160; e Platão $\mathrm{III}^{\circ}$ e X $\mathrm{X}^{\circ}$ livro República.
} 
Em outras palavras, inserimo-nos no simbólico da cultura e crescemos em nosso acesso ao Ser, para empregar a expressão heideggeriana, isto é, nos descobrimos mais ricos nos apropriando ou, melhor, integrando esse simbólico. Por meio da impressão e da sensação, toda arte, seja ela qual for, marca um avanço dos homens de qualquer origem social na cultura. Subsistirá ainda alguma distinção entre a cultura popular, a cultura erudita e a cultura folclórica, entre uma cultura nacional ou outra? A cultura, qualquer que seja, transporta os homens para além deles mesmos ou do que crêem ser. Em outras palavras, "continuamos sendo alguém, um animal humano como os outros, que, no entanto, viu-se pego e deslocado pelo processo factual de uma verdade" ${ }^{, 51}$ por meio da arte.

Tocamos aqui um ponto crucial das relações entre a psicanálise e as artes. A psicanálise não tenta mais confirmar seus achados na literatura nem desvelar o inconsciente do escritor como Freud interpretando a Gradiva ou o quadro de Sainte Anne, la vierge et l'enfant Jésus de Leonardo da Vinci. São coisas do passado. As artes participam do vasto movimento que tira os homens de sua condição finita e lhes proporcionam viver numa dimensão maior. A psicanálise colabora para esse movimento desfazendo o estabelecido e os preconceitos, demolindo as barreiras entre os seres, exigindo uma narrativa do analisando que permite reconstituir uma história singular que o distingue dos demais.

O procedimento do herói proustiano é parecido, já que inclui Albertine num romance, numa melodia ou num quadro. O deslocamento da realidade empírica - Albertine -, para sua inclusão numa estrutura narrativa, melódica ou de cores, é o mesmo movimento que faz o analisando, deslocando alguns fatos de sua vida para uma narrativa. A estrutura da língua, da melodia ou de cores tem a vantagem de ex-sistir e de estar fora do homem.

O que chamei "campo do gozo estético" é semelhante a essa zona de trabalho da psicanálise que ocupa o lugar central da cena analítica, a transferência. ${ }^{52} \mathrm{O}$ espaço de trabalho de uma análise não é o gabinete do psicanalista, mas a transferência criada entre o analisando e seu analista que inventa um laboratório no qual, nas palavras de Freud, "conseguimos substituir a neurose ordinária (do analisando) por uma neurose de transferência que o trabalho terapêutico vai sanar". ${ }^{53}$

A página branca, suporte do campo de gozo do escritor, não registra uma neurose necessariamente, mas uma idéia ou um plano inicial que vai se transformar nas versões sucessivas até o texto publicado, movido pela inspiração definida como "o fato de o autor ser trabalhado pela atividade de criação". 54

Nesses dois espaços entram elementos muitas vezes sem nexos evidentes, mas que, aos poucos, se articulam, voltam e agem no escritor ou no analisando que se tornam efeitos de seu discurso. A distribuição das características entre uma personagem e outra planejada de certa maneira numa versão é redistribuída na versão seguinte em Flaubert e Proust. De três romances programados, Proust teve que interromper a publicação em razão da guerra de 1914-1918, e escreveu mais quatro volumes que o forçaram a reestruturar o previsto inicialmente.

Continuando a comparação entre o processo psicanalítico e a escritura, sabemos que o analisando confia totalmente no analista, supondo um saber que ele não tem. É o famoso S-S$\mathrm{S}$, o sujeito-suposto-saber que implica uma entrega ao processo analítico e faz funcionar a transferência. Da mesma forma, o escritor confia na escritura e acredita, que rascunhando, preenchendo a folha de papel em branco, as idéias, o enredo, as personagens virão se alinhar

\footnotetext{
${ }^{51}$ Alain Badiou, L'éthique, Paris, Nous, 2003, p. 117.

${ }^{52}$ Isabelle Stengers, La volonté de faire science. A propos de la psychanalyse, Paris, Les Empêcheurs de Tourner en Rond, 1992, p. 43.

53 Sigmund Freud, "Remémoration, répétition, perlaboration", in La technique psychanalytique, Paris, PUF, 1985, p. 113-14.

${ }^{54}$ Marie-Helene Paret Passos, Crítica genética e tradução literária: o caminho da recriação e da reescritura, Porto Alegre, 2007. Tese (Doutorado) - Faculdade de Letras, Universidade Federal do Rio Grande do Sul.
} 
para constituir a narrativa. $\mathrm{O}$ escritor percorre a escritura com a mesma fé que o analisando explora seu discurso pontuado pelo psicanalista. A última versão da obra é, portanto, comparável ao fim do processo psicanalítico. A obra ocupa a posição do fim da análise, já que a obra por vir e desconhecida no início advém ao longo da escritura, como o fim da análise desabrocha ao longo do discurso do analisando.

No entanto, a comparação vai mais longe. $\mathrm{O}$ escritor rasura bastante antes de entregar seu texto ao editor. Flaubert deixou 4.500 fólios rasurados para Madame Bovary que contém apenas 470 fólios na última versão. O que seria a rasura no gabinete do analista? São as pontuações do analista que obrigam o analisando a bifurcar, se deixar levar por outras palavras ou expressões, por outros rumos para contar sua história e se dizer de outro modo.

O alvo da análise é parecido ao da escritura, embora se distinga. A análise visa ao desser ou à revisão de todas as identificações do sujeito para chegar ao traço unário ou à letra, ${ }^{55}$ espécie de início de contagem a partir do qual se constituiu o sujeito, é o Dasein heideggeriano (tu es cela!) no qual o analisando se reconhece. ${ }^{56}$

A arte não chega ao des-ser necessariamente e não tem essa finalidade. No entanto, ela também descobre outro sujeito no fim do processo, a saber, uma instância diferente de quem começou a escrever, uma instância que passou de rascunho em rascunho até a entrega ao editor. É o autor. Nesse sentido, a escritura fez furo no imaginário do escritor. Ele imaginava ser apenas tal pessoa e conseguiu por meio da escritura arrombar a imagem que tinha dele mesmo.

Assimilar o analisando ao escritor não seria confundir as duas posturas? Sim e não. Tanto um quanto o outro se submetem à linguagem e se dizem entre as palavras pelo meiodizer. Mas enquanto o escritor tem em geral um plano e constrói sua narrativa - Proust comparava sua obra a uma catedral a ser construída -, o analisando deixa-se levar pelas associações que, embora ditas livres, seguem sem saber um simbólico inconsciente. Entretanto, essa divisão entre consciente e inconsciente, saber e ignorância, é muito frágil, já que uma organização claramente voluntária pode esconder uma dimensão inconsciente. Além disso, há momentos em que o escritor, por mais planejador que seja, se deixa levar pela escritura e pelas associações. Tudo não é controlável. Zola mesmo, que seguia rigorosamente seus esboços, é surpreendido em certos momentos pela palavra inscrita que o obriga a rasurar e a desviar do plano inicial.

Reparamos, no entanto, que ambos, o analisando e o artista, podem ir além e comungar numa outra procura. Voltando ao ponto $\mathrm{K}$ pessaniano ou ao traço unário freudiano para o primeiro ou ao trabalho do significante para o segundo, os dois poderiam mergulhar numa terceira dimensão que recorta uma quarta. Eu me refiro ao "jadis" ou ao "outrora" de Pascal Quignard. Freud tinha sublinhado que somos fruto de quatro gerações, ${ }^{57}$ Quignard amplia a ascendência e acentua a importância de toda a biosfera da qual o homem é fruto, desde o reino animal, os pássaros, os camarões até os macacos, passando pelos tigres que sonham mais do que o homem etc. O homem acumula paixões, gostos e hábitos daqueles que o antecederam nos milhares de anos da história, os quais são guardados na memória por meio da linguagem, dos gestos ou das palavras, ${ }^{58}$ e prontos a ressurgir na ocasião da montagem de uma obra de arte ou no decorrer de uma análise.

Reencontramos o episódio do herói proustiano. Recolocando sua amante num livro, num quadro ou numa melodia, a obra vive de novo e reanima o desejo: "sentia afetos ardentes" - é a função do cotidiano -, e em segundo lugar, Albertine é transportada num

\footnotetext{
55 Ana Vicentini Azevedo, "Aquilo que faz furo na consistência imaginária” in Tânia Rivera, Vladimir Safatle, (org.) Sobre arte e psicanálise, São Paulo, Escuta, 2006, p. 23. Tânia Rivera, Vladimir Safatle, "Ruídos da Imagem", in Idem (org.) Sobre arte e psicanálise, op. cit., 2006.

${ }^{56}$ Jacques Lacan, Escritos, Rio de Janeiro, Zahar, 1998, p. 45.

${ }^{57}$ Sigmund Freud, Moïse et le monothéisme, Paris, Gallimard, 1948, p. 177.

${ }^{58}$ Pascal Quignard. Abîmes, Paris, Gallimard, 2002, p.188 ss.
} 
mundo no qual ela "escapa [...] à esmagadora pressão da matéria para espairecer nos fluidos espaços do pensamento". Bicéfala, a amante, "enfadonha" antes, se faz desejar de novo, mas também circula na mente do herói desprovida do corpo como se fosse apenas um espírito, uma idéia ou uma essência que se enquadra na "obra de Elstir ou de Bergotte". Isto é, a amante entra na mente do herói porque se tornou personagem ou ficção de uma obra ligada a um simbólico que evidentemente a ultrapassa. A linguagem da arte - a escritura, a pintura ou a música - escreve o herói. Ele se diz ou se descobre outro sujeito percorrendo essas linguagens que o relacionam com a história e a filosofia dessas artes e adquire assim uma dimensão universal.

Essa terceira dimensão recorta, entretanto, uma quarta entrevista na leitura da análise do Moisés de Michelangelo por Freud:

Michelangelo capta o momento que sucede imediatamente a abertura de Moisés a algo profundamente ancorado nele mesmo e deixa languescer o espectador, que aspira também ao gozo entrevisto. A obra de arte é vivida como uma amostra do encontro com a Coisa (Das Ding), esse objeto primordial do desejo que só deixou saudades e cujo lugar é habitualmente ocupado pela mãe. É um deslocamento típico, ou um encontro malogrado, que força Freud, cativado, a ir lá todos os dias para "suportar o irado desprezo do olhar do herói" ${ }^{9}$ como se quisesse enfrentar o Real, sentir seus efeitos, mesmo que, eventualmente, sendo a tensão demasiadamente forte, tivesse de abrigar-se na igreja ao lado. ${ }^{60}$

Marilia Panitz, analisando a obra de Andréa Campos de Sá e Walter Menon, salienta no mesmo sentido que "trata-se [...] de fendas pelas quais se vislumbra o que não é passível de simbolização", 61 isto é o Real lacaniano.

Se a escuta psicanalítica tem como função a reconstituição lógica da história do analisando sobre três ou quatro gerações e a tentativa de nomear o Real subentendido, ${ }^{62} \mathrm{o}$ escritor, por meio da escritura, elabora uma ficção, uma poesia ou um drama se submetendo à linguagem e tentando, muitas vezes sem saber, captar também um pedaço de Real, não necessariamente na história dele, mas na sociedade em que vive.

Vejo assim as relações entre a literatura e a psicanálise como uma trama na qual os fios dos dois campos e seus conceitos se misturam para detectar o que há de comum e ver os avanços de um e de outro. Não se trata de descrever a obra de arte para aí encontrar os mecanismos detectados por Freud e seus discípulos, nem de aplicar os conceitos psicanalíticos à obra. Trabalhar hoje as relações literatura-psicanálise exige do crítico não só um conhecimento dos dois saberes, mas a flexibilidade suficiente para ao mesmo tempo não confundir os objetivos dos dois campos e estabelecer as relações não a partir da psicanálise nem da literatura, mas da procura de uma compreensão maior do ser humano. É o que sustenta Pontalis em Fenêtres ter permitido reunir literatura e análise. É quase um novo gênero. Nem psicanálise nem literatura, nem ensaio nem ficção. A análise não é o objeto, mas a fonte. Fenêtres significa "vamos respirar, saímos do harém, do bairro, da corporação". 63

Ainda sobra uma pergunta. Escrever, pintar, esculpir ou inventar uma melodia substitui uma análise? A resposta é ampla, mas para ser breve, diria que enquanto a análise abre o analisando a seu mundo desconhecido, a prática da arte abre o artista ao novo no mundo, incluindo ou não sua trajetória pessoal. A arte não substitui a análise nem a análise a

\footnotetext{
${ }^{59}$ Sigmund Freud, O Moisés de Miguelangelo, Rio de Janeiro, Imago, 1974, p. 255.

${ }^{60}$ Philippe Willemart, Além da psicanálise: a arte e a literatura, São Paulo, Nova Alexandria, 1995 p. 34.

${ }^{61}$ Marília Panitz, "O que os olhos não vêem...", in Tânia Rivera, Vladimir Safatle (org.) Sobre arte e psicanálise, op. cit., p. 98.

62 Philippe Garnier, Psychanalyse et anarchie: à propos de l'ordre moral. Disponível em: $<$ http://1libertaire.free.fr/Garnier21.html>.

${ }^{63}$ Disponível em : <http://www.lire.fr/entretien.asp?idC=38990\&idR=201\&idTC=4\&idG=>.
} 
arte, mas ambos os processos usando uma linguagem determinada trabalham o Real mais ou menos centrados no sujeito por meio do Imaginário para tentar arrancar um pedaço desse Real e simbolizá-lo até "que não consista em deixar a obra semelhante ao sujeito, mas o sujeito semelhante a ela". 64

${ }^{64}$ Theodor W. Adorno, AT, p. 33, apud Vladimir Safatle, A paixão do negativo, São Paulo, Unesp, p. 287. 